\title{
Yağmur Sularının Hasadı ve Aktif Olarak Tarımsal Sulamada Kullanılması
}

Mikail YENİÇER'́1

\section{Özet}

Dünya'nın dörtte üçünün suyla kaplı olmasına karşın bu suyun yalnızca belli bir kısmı (\%3) içme suyu ve sulamada kullanılabilmektedir. Yağmur suyu ise su döngüsünde bu su kaynaklarının beslenmesi için en önemli basamaklarından biridir. Bununla beraber bu kaynakların da bilinçsiz bir şekilde kullanımının (hem içme suyu hem de tarımsal sulama) artması nedeniyle su kaynakları hızla tükenmektedir. Bu durumun devam etmesi neticesinde Dünya'da gelecekte su sıkıntısının görülmesine neden olacaktır. Tarımsal sulamada Dünya'nın birçok bölgesinde yağmur suyu hasadı yöntemi kullanılmaktadır. Bu yöntem ile yağmur suları değerlendirilmekte ve su israfının önüne geçilmektedir. Üç tarafı denizler ile çevrili olmasına rağmen Ülkemiz su stresi çeken ülkelerden biridir. Bu nedenle yağmur suyu hasadı yöntemi kullanım alanının artırılmasına yönelik çalışmalar ve teşvikler Ülkemiz için kazanç olacaktır. Bu çalışmada, yağmur suyu hasadı sonucu elde edilen suyun, hızla tükenmekte olan su kaynakları nedeniyle yaşanan su kıtlığına alternatif olarak tarımsal sulamada yeniden kullanılması tartışılmıştır.

Anahtar Kelimeler: Su, Yağmur Suyu Hasadı, Tarımsal Sulama

\section{Harvesting of Rain Water and Active Use In Agricultural Irrigation}

\begin{abstract}
Although three-quarters of the world is covered with water, only a certain part (3\%) of this water can be used in drinking water and irrigation. Rain water is one of the most important steps for feeding these water resources in the water cycle. However, water resources are rapidly depleted due to the increase in unconscious use of these resources (both drinking water and agricultural irrigation). As a result of this situation, it will cause water shortage in the world. Rain water harvesting method is used in many parts of the world in agricultural irrigation. With this method, rain water is evaluated and water wastage is prevented. Although it is surrounded by seas on three sides, our country is one of the countries suffering from water stress. Therefore, studies and incentives to increase the usage area of rainwater harvesting method will be the gain for our country. In this study, the water used as a result of rainwater harvesting as an alternative to water scarcity due to rapidly depleted water resources is discussed.
\end{abstract}

Keywords: Water, Rain Water Harvesting, Agricultural Irrigation

${ }^{1}$ Çevre Mühendisi

İlgili yazar / Corresponding author: myeniceri@ahievran.edu.tr

Bu makaleye atıf yapmak için- To cite this article YENIÇERİ, M. (2018). Yağmur Sularının Hasadı ve Aktif Olarak Tarımsal Sulamada Kullanılması. Afet ve Risk Dergisi, $1(2), 126-136$. 


\section{GÍRIŞ}

Su canlı varlıkların yaşamlarını sürdürebilmeleri için en önemli gereksinimlerden biridir. Dünya haritasına bakıldığında görülen maviliklerin sadece \%2,5'ini tatlı sular oluşturmaktadır. Tatlı suların \%70'ini ise buzullar oluşturmakta ve kullanılabilir tatlı su miktarı dünya su varlığının $\% 1$ 'inden daha az bir kısmına karşı gelmektedir. Halen dünya nüfusunun yaklaşık beşte biri $(1,2$ milyar kişi) su sıkıntısı çeken yerlerde yaşarken, diğer yandan 1,6 milyar kişi ise altyapı yetersizliği ve ekonomik nedenlerle sağlıklı suya ulaşamamaktadır. Önümüzdeki 40 yıl içerisinde dünya nüfusunun $\% 40$ artacağı beklenmektedir. Nüfusun artması ile birlikte suya olan talepte artacaktır. Son yüzyıl içinde dünya nüfusu üç kat artarken, su kaynaklarına olan talep yedi kat artmıștır. Dolayısı ile suya olan talep nüfus artıșına oranla çok daha fazladır. Tatlı su kaynaklarının yaklaşık \%70'i tarımda kullanılmaktadır. Artan nüfusun yanı sıra gelir ve tüketim düzeyinin yükselmesi ve gıda ürünlerine yönelik taleplerin artması da su kaynakları üzerinde ilave baskı yaratmaktadır. İçme ve kullanma amaçlı tüketilen suyun yüzde yetmiş (\%70)'ini tuvaletler, bahçe sulama, araç ve çamaşır yıkama gibi işlemler oluşturmaktadır (Eren vd., 2016).

Kentleşmenin hız kazandığı 21. yüzyılda, dünya nüfusunun yarısı kentsel alanlarda yaşamakta ve bu oran her geçen gün artmaktadır. Yaşamın devamlılığı için temel bir doğal kaynak olan suyun korunması ve etkin kullanılması, günümüzde özellikle insanoğlunun temel yaşam alanı haline gelen kentlerde hayati bir konu haline dönüşmüştür. Kentler doğal alanlara oranla suyun infiltrasyonunu engelleyen daha büyük miktarda geçirimsiz yüzeylere sahip olmaları nedeniyle dikkate değer oranda yüzeysel akış oluşturmaktadır. Geçirimsiz yüzeylerde görülen artış, genellikle yüzeysel akış miktarını, anlık en yüksek akımları, kirletici yükünü ve yoğunluğunu arttırmaktadır. Bunun sonucu olarak, su kaynaklarını tehdit eden kentsel alan kullanımının iki ana ürünü, kanalizasyon (ve endüstriyel atıklar) ile yüzeysel akış olarak karşımıza çıkmaktadır (Ekşi vd, 2016).

Yağmur hasadı, kurak bölgelerdeki yağmur mevsimlerinde çeşitli yöntemlerle suyun yer altı ve yer üstü depolarda toplanmasıdır. Çok miktardaki yağmur suyunun biriktirilmesine barajlar ve sarnıçlar örnek olarak verilebilir. Ayrıca evde ve tarım alanlarında yağmur suyu hasadı başarılı bir şekilde uygulanabilmektedir (URL 1).

Dünya üzerindeki kurak ve yarı kurak alanlarda yağmur sularının hasadı sonucu toplanan su ile bu bölgelerde su kullanım oranı ve verimin artması sağlanacaktır. Aynı zamanda yağmur suyu hasadı ile yağmur sularının boşa akması önlenerek, gittikçe artmakta olan su kıtlığına üretilen bir alternatif çözüm olacaktır. Dünya'daki kurak ve yarı kurak bölgelerde bulunan kırsal yerlerde yanlış su kullanımı ve büyük ziraat alanları bölgedeki tatlı su miktarını azaltan etkenlerdendir. Göller ile yer altı suları bulundukları bölgenin su rejimini düzenlemekte, bölgede tarımsal sulama için açılan izinsiz kuyular göllerden su çekilmesine neden olmakta böylece yer altı su düzeyleri giderek azalmaktadır. Bu işlemler sonucunda yüzey sularında yenilenme olmadığından bu durum geri dönüşü olmayan sonuçlara yol açacaktır. Diğer yandan tarım alanı açmak amacı ile hatalı mera yönetimi sonucu yok edilen ekosistem biyoçeşitlilik ve ekosistemin devamlılı̆̆ açısından çok büyük bir kayıplara neden olmaktadır (URL 2).

\section{TARIMSAL YAĞMUR SUYU HASADI}

Yağmur hasadı, yağmur suyunun tutulması sonucu suyun yeryüzü ya da yer altı ile toprakta veya kullanıma göre depolarda biriktirilmesi metodudur. Yağmur hasadı, tarımsal sulamada ve konutta kullanılan ve devamlılık arz etmeyen yer altı suyu kullanımı yerine yağış olarak yeryüzüne düşerek yüzey akışına geçen suyun biriktirilerek kullanılmasına yönelik geliştirilen metotların tamamıdır. Yağmur hasadı; kendisini bütünleyen gıda ormanı, yer örtüsünün ve topraktaki organik içeriğin artırılması gibi yan uygulamalarla, toprağın iyileştirilmesi, yer altı suyunun beslenmesi, susuzluk nedeniyle kısıtlanan tarımsal üretimin ve veriminin artırılması, göletler içinde balık ve uygun bitki üretimi yanı sıra su kuşlarına habitat oluşturma gibi ekolojik ve rekreasyonel faydalar sağlamaktadır (URL 2). 
Yağmur Sularının Hasadı ve Aktif Olarak Tarımsal Sulamada Kullanılması

Su hasadı yöntemi, yağmur gibi yağış sularından en üst düzeyde yarar sağlamayı amaçlayan bir yöntem olup, yağış suları ve yüzeye toplanan suların biriktirilmesi ayrıca bitki ve hayvan kaynaklı gıdaların üretiminde gereken suyun tedarikinde kullanılan bir yöntem olarak belirtilebilir. Su hasadı yönteminin ana gayesi; yeraltı ve yerüstü su kaynaklarının yetersiz olduğu ya da bu kaynakların geliştirilmesinin ekonomik olarak zor olduğu bölgelerde güvenilir bir su elde edilmesini sağlamaktır. Su hasadı yöntemine uygun bölgeler, nemin yarı yarıya olduğu, kurak ve yarı kurak alanlar ile düșen yağıș oranı az olan bölgeler, sıcaklığın yüksek olması gibi sebeplerle su sağlamanın bitkilerin su gereksiniminden az olduğu bölgeler ile yıllık yağış miktarının 150 mm'yi geçtiği ve yağışın kış mevsiminde yağdığı bölgeler, yıllık yağış miktarının 200 mm'yi geçtiği ve yağışın yaz mevsiminde yağdığı bölgeler ile su deposu veya havuzda biriktirilemediği bölgeler su hasadı yapılmasına elverişli olan alanlardır (Ekinci, 2015).

Negev Çölü (İsrail)'nde yıllık 100 mm yağış miktarı olan bölgelerde bulunan ziraat ve mesken alanlarında yamaçlardan gelen yağışı biriktirmek amacıyla tanklardan yararlanılmaktadır. Ayrıca Mısır'da aşağı yukarı 2000 senedir kullanılarak günümüze gelen 200-2000 m³ lük depolardan bugün bile hâlâ faydalanılmaktır. Benzer uygulama Asya kıtasında Tayland'da aşağı yukarı 2000 senedir görülmektedir. Çok eski zamanlardan beri Afrika ve Asya kıtalarında geleneksel olarak toprak kaplar içinde yağmur sularının toplanması yöntemi kullanılmaktadır. Filistinli çiftçiler aşırı yağışlardan kaynaklanan zararlı etkileri azaltmak, erozyonu ve akıp gitmeyi önleyerek topraktaki organik madde miktarını yükseltmek ve mevcut toprak su yapılarını muhafaza etmek için taştan teraslar kurmuşlardır. Yağışın düştüğü yerde tutularak toprak profilinde saklanması biçiminde uygulanan su hasadı teknikleri bulunmaktadır (Ekinci, 2015).

Erozyonu ve çökeltmeyi azaltmada, suyun toprakta depolanmasında ve toprak verimliliğinin artırılması gayesiyle uzun zamandır su hasadı teknikleri uygulanmaktadır. Su hasadının avantajları arasında kolay, pahalı olmayan, tekrarlanabilir, tesirli ve uyumlu olması sayılabilir. Bunun yanı sıra su hasadının pek çok sosyal ve ekonomik faydalarının yanında aynı zamanda yeraltı suyuna olan ihtiyaç azalmakta ve su tüketim giderleri düşmektedir. Eğer geçirgenliği oldukça yüksek olan bölgelerde saklanan su miktarı fazla olursa, suyun bir bölümü de yeraltı suyunu da beslemektedir. Su hasadını sulamadan ayıran en önemli fark zamanlama olarak çiftçilerin kontrolünde olmamasıdır. Yüzey akış hasadı sadece yağışın olduğu durumlarda yapılabilmektedir. Sadece yağışlarla beslenen bitkilerin olduğu bazı bölgelerde yıllık yağış miktarındaki yarı yarıya bir azalma, toplam verimde önemli düşüşlere neden olabilir. Buna ek olarak yağış çok ufak bir bölgede biriktirilirse uygun bir verim elde edilebilecektir (Benliay, 2017). Su hasadı tekniği iki kısımdan oluşur:

1. Akışın toplandı̆̆ yer

2. Akışın kullanıldığı yer (Şekil 1) (Ekinci, 2015).

\section{Yağmur suyu ve özellikleri}

- Sertlik yapıcı iyonları (kalsiyum, magnezyum, karbonat) içermediğinden çamaşır yıkama ve yemek pişirmede kullanılabilecek kalitede su yapısı vardır.

- Herhangi bir ücreti yoktur (URL 2).

\section{Yağmur suyunu tutmanın faydaları}

Erozyonun oluşumunu önlemeye yardımcı olur.

İçme suyu kalitesini arttırır.

$>$ Su kirliliğini önlemeye yardımcı olur.

$>$ Bitki örtüsünü ve hayvanları beslemeye yardımcı olur.

$>$ Su taşkınlarını ve seli önlemeye yardımcı olur. 
Afet ve Risk Dergisi Cilt: 1 Sayl: 2, 2018 (126-136)

Mikail YENİCERİ

Tarımda kullanılan suyun kalitesini arttırır.

Su tutma bölgelerindeki balıklar sayesinde sivrisinek vb. canlıların aşırı çoğalmasını önler.

> Yer altı sularının çoğalmasını ve beslenmesini sağlar.

> Taşkın ve seli kontrol etmek için inşa edilen drenaj kanallarının maliyeti ile yapılan işçilik giderini de ortadan kaldırır.

$>$ Tuz oranı diğer doğal tatlı sulara göre az olduğundan bitkilere çok faydalıdır.

$>$ Topraktaki üretimi artırır (URL 2).

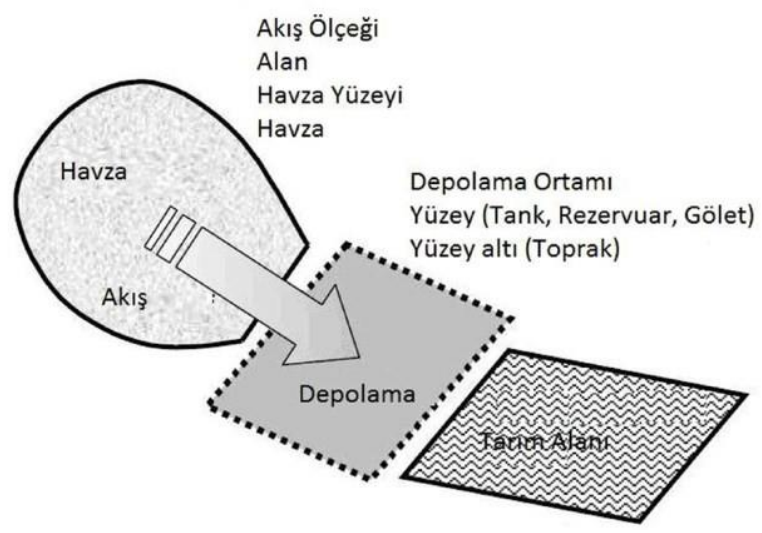

Şekil 1. Bitkisel üretim için su hasadı (Ekinci, 2015)

\subsection{Tarımsal Yağmur Suyu Hasadı Teknikleri*}

Tarımsal yağmur suyu hasadı çok eskilere dayanan ve Dünya üzerindeki pek çok kurak bölgede kullanıldığından çok sayıda değişik tekniğin geliştirilmesine yol açmıştır. Yağmur suyu hasadı yöntemlerinde sınıflandırma kullanım ve ya depolama türüne göre yapılabilir lakin su biriktirme sahası büyüklügüne göre yapılan sınıflandırma en yaygın olarak kullanılmaktadır. (Ekinci, 2015). Şekil 2'de tarımda kullanılan yağmur suyu hasadı yöntemleri gösterilmektedir.

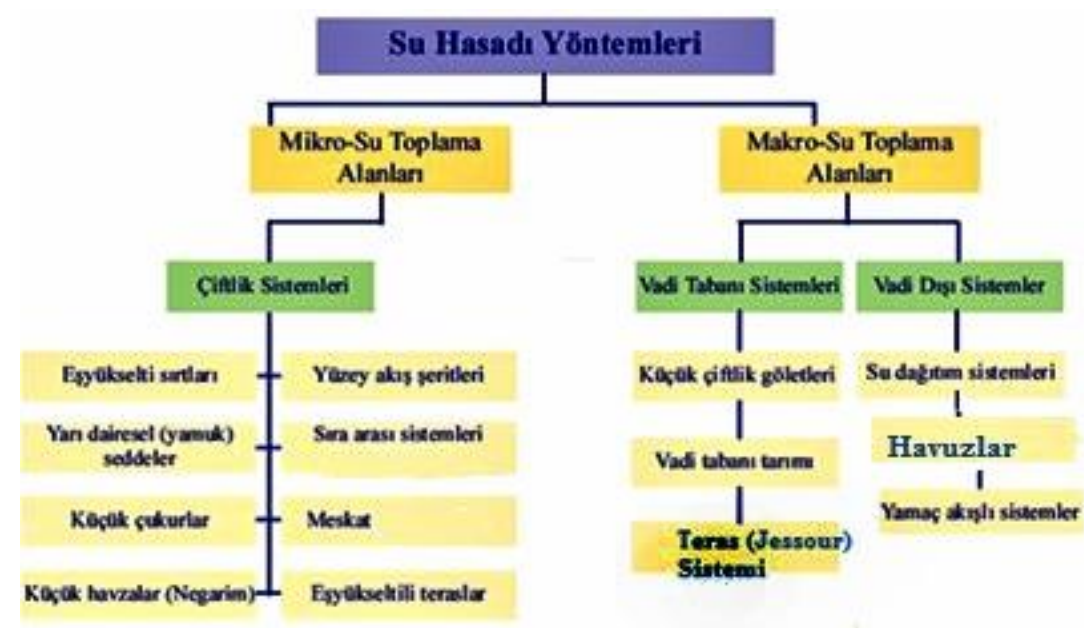

Şekil 2. Yağmur suyu hasadı yöntemlerinin sınıflandırılması (Ekinci, 2015)

*Bölüm 2.1 Ekinci (2015)'nin çalışmasından alınmıştır. 


\subsubsection{Mikro Su Toplama Alanı Sistemleri}

Toprak yüzeyinde biriken yüzey akışının toplandığı mikro havza su hasadı yönteminde, ağaç, çalı ile tek yıllık bitkiler yetiştirilebilir (Ekinci, 2015).

\subsubsection{Ciftlik Sistemleri}

Ciftlik mikro-su toplama alanlarını tasarlamak hem kolaydır hem de az bir maliyetle yapılmaları tatbik edilebilirliklerini ve uyumluluklarını arttırır (Ekinci, 2015).

\section{Eşyükselti Sirtları}

Yıllık yağış miktarının 300-600 mm olduğu ve eğimin \%1-25 arasında olduğu bölgelerde kullanılmakta olup, düşük eğimli bozkır bölgelerinde yem bitkileri, çim ve dayanıklı ağaçlar için, yarı kurak iklim şartlarında ise, sorgum, çavdar, fasulye ve börülce için kullanılan elverişli bir tekniktir (Ekinci, 2015) (SSekil 3a).

\section{Yarı Dairesel (Yamuk) Seddeler}

Toprakta oluşturulan yarı dairesel yarım daire biçiminde farklı genişlikteki dolgular olup, meraların ıslahı ve yem bitkileri üretiminde kullanılan setlerdir (Ekinci, 2015) (Şekil 3b).

\section{Küçük Çukurlar}

Toprak yüzeyindeki çukur seddeleri aracılı̆ğyla yüzey akış suları yavaşlatılarak saklanır ve verim yönünden yetersiz olan tarım alanlarının tekrar kullanılmasına olanak sağlar. Tek yıllık ürünler için kullanılan teknik olup, "zay"sistemi Burkina Faso'da kullanılan ve en çok bilinen çukur sistemidir (Ekinci, 2015) (Sekil 3c).

\section{Küçük Akışlı Havzalar}

Her çeșit akış havzasında oluşturulabilen ve yerden yüksekliği az olan toprak seddeleri tarafindan sarmalanmış küçük elmas ya da dikdörtgen șeklindeki ızgara toprak setleri olup, negarim" olarakta adlandırılmaktadırlar. Kayısı, zeytin, badem, nar ve Antep fistığı gibi meyve ağaçları için Ortadoğu'da bu teknik kullanılmaktadır. Bununla birlikte, bu teknik ağaçlandırma ve hayvanların beslenmesi için çalı kurulumunda da kullanılmaktadır (Ekinci, 2015) (Şekil 3d).

\section{Yüzey Akış Şeritleri}

Çok dik olmayan araziler için uygun olan bu teknik, kuru tarımın yapıldığı bölgelerde, bilhassa verimin düşük ve riskin olduğu alanlar ile tarla bitkilerine destek amacıla kullanılmaktadır (Ekinci, 2015) (Şekil 3e).

\section{Sira Arası Sistemleri}

Yağan yağmur miktarının verimli bitki yetiştirilmesine imkân olmadığı alanlarda yapılan mikro havza su hasadı tekniklerinden biri olup, bitki ekili alana karlk ve sirt şekli verilerek uygulanmaktadır. Bitkiler arasındaki sirt şeklindeki bölgenin üstü malç örtüyle ya da buradaki toprak sıkıştırılmaktadır. Sırtlara düşen yağmur suyu karıklarda ekili olan bitkilere yönlendirildiğgi bu teknik düz alanlarda uygulanan en yararlı tekniktir (Ekinci, 2015) (Șekil 3f).

\section{Meskat Sistemler}

Tunus'ta yerel halk arasında kullanılmakta olan meskat sistemler, yıllık yağış miktarının 200-400 mm ve eğim düzeyinin \%2-15 arasında olduğu bölgeler için uygulanan sistemlerdir. (Ekinci, 2015).

Es Yükseltili Teraslar

Yüzey akış sularını kesmek amacıyla eğim olan bölgeye çapraz olarak uygulanan setlerdir. Bu setler suyun hızını sabit bir şekilde çıkışa ileterek erozyonu önlemede ve eğimin uzunluğunu azaltmada kullanılmaktadır (Ekinci, 2015) (Şekil 3g). 

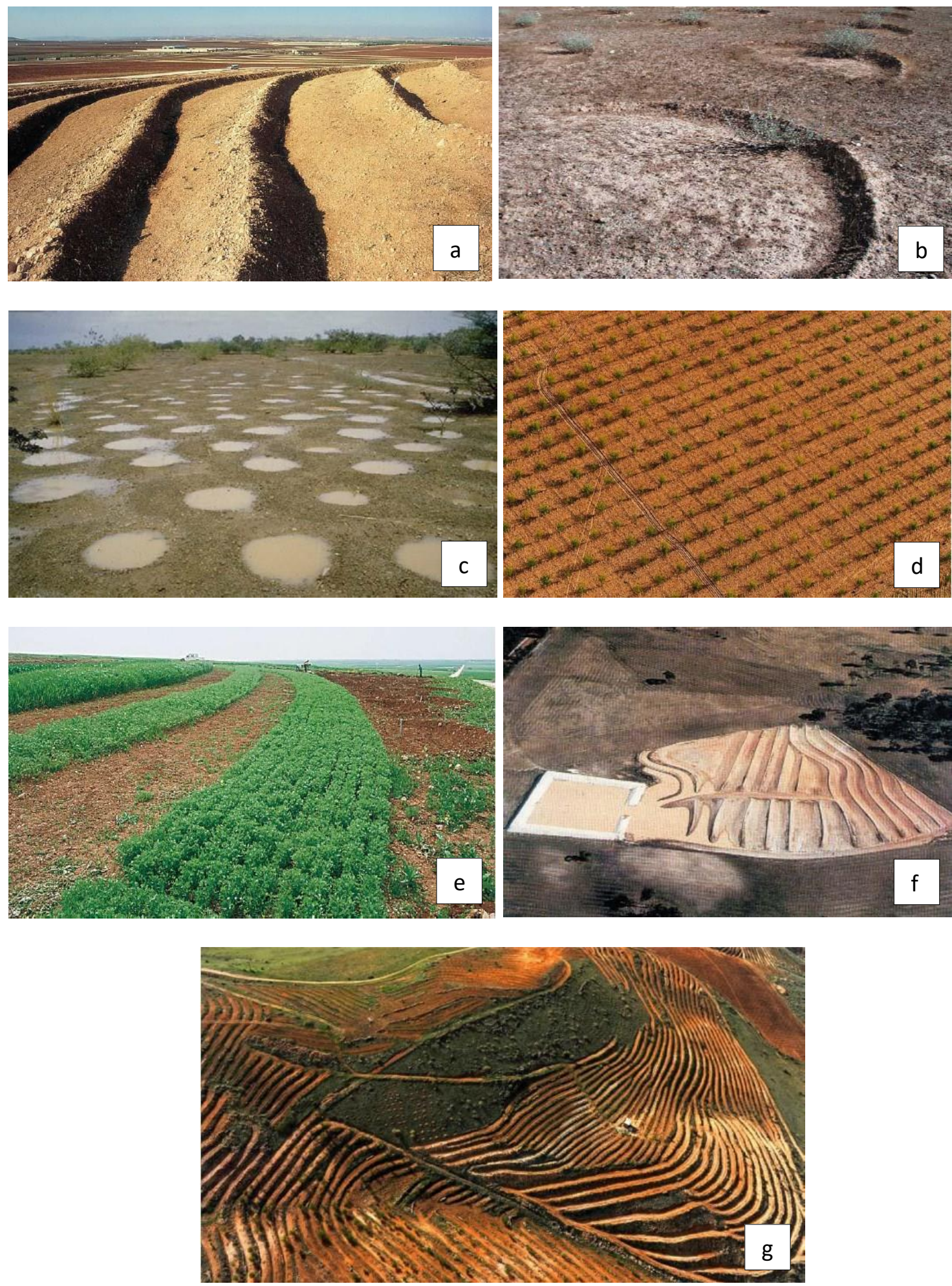

Şekil 3. Mikro Su Toplama Alanı Sistemleri (Ekinci, 2015); a) Suriye'de bulunan ICARDA araştırma çiftliğinde yapılan sirtlar), b) Arazide kademeler halinde dizilmiş yarı dairesel seddeler, c) Zay sistemi, d) Negarim ile düzenlenmiş bir arazi, e) Yüzey akış şeritleri, f) Avustralya'daki bir gölette yüzey akışı toplayan sıra arası sistemi, g) Eş yükselti terasları. 
Yağmur Sularının Hasadı ve Aktif Olarak Tarımsal Sulamada Kullanılması

\subsubsection{Makro Su Toplama Alanı Sistemleri}

$\mathrm{Bu}$ sistemde toprak yüzeyindeki akışın toplanmasında makro havza su hasadı yönteminden faydalanılmakta olup ekim alanının yüzey akış katsayısını arttırmak için önlemler alınabilmektedir. Diğer yandan toplanan suyun çoğu toprakta biriktirilmekte ve suyun fazlası uzaklaştırılmaktadır. Dünya'nın pek çok bölgesinde taşkın suyundan ağaçlandırma yapmak amacıyla faydalanılmaktadır. Taşkın suyu hasadı, yüzey akış suyunun aktığı geniş bir bölgeyi, kompleks bir baraj ve dağıtım ağlarına gereksinim duyan sistemleri içine almaktadır. Bu yöntemle debisi mevsimlere göre değișen akarsu akıșı toplanmaktadır. Ayrıca bu yöntem ani tașkınların verdiği olumsuz etkileri azaltmakta ve bitkisel üretimde gerekli olan besleyici ürünlerin alınmasına katkı sağlamaktadır (Ekinci, 2015) (Şekil 4).

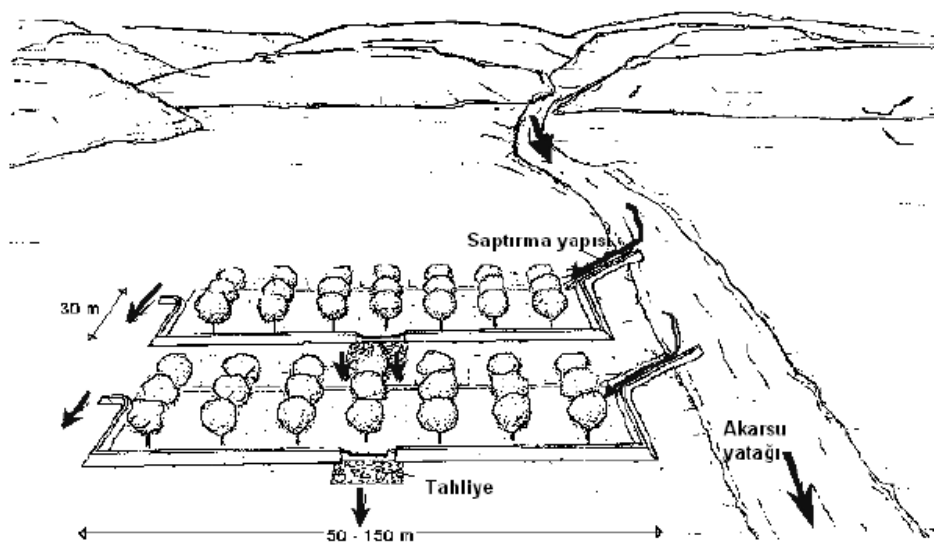

Şekil 4. Taşkın hasadı örnek șeması (Ekinci, 2015)

\subsubsection{Vadi Tabanı Sistemleri}

Küçük Çiftlik Göletleri

Çoğunluğu ufak olan bu göletlerin su alma kapasiteleri ara sira $1000 \mathrm{~m}^{3}$ 'ten $500.000 \mathrm{~m}^{3}$ 'e $\mathrm{kadar}$ çıkabilmektedir. Bu kapasitedeki en önemli unsur vadiden geçebilecek en yüksek akış için yeterli kapasitedeki bir dolu savağın olmasıdır. Bozkır bölgelerde oluşturulan küçük çiftlik göletleri bu alanlarda çok önemlidir. Oluşturulan göletler bölgede bulunan bütün tarımsal ürünlere su sağlar ve üretimi artırır, ayrıca bölgeyi stabil duruma getirir. Ek olarak bu göletler çevresine de katkı sağlamaktadır (Ekinci, 2015) (Şekil 5a).

Vadi Tabanı Tarımı

Eğimin düşük olduğu vadi tabanlarında kullanılan bu teknikte, su hızı düşük olduğundan taşınan toprak parçacıkları çoğunlukla vadi tabanına çökmekte ve iyi tarım bölgeleri ortaya çıkmaktadır. Vadi tabanında bulunan toprağın verimli ve su miktarı da yeterli olduğu için bölgede incir, zeytin, hurma ve diğer ekonomik değeri yüksek olan meyve ağaçları yetiştirmek için bu tekniğin kullanılması çok yaygındır. Maliyet ve duvarların onarımı bu teknikte karşılaşılan başlıca sorunlardandir (Ekinci, 2015) (Şekil 5b).

\section{Teras (jessour) Sistemi}

Yamaç eteklerinde ya da mevsimlik dere kanalları arasına inşa edilerek yapılan toprak, kaya veya kafes şeklindeki küçük barajlardan oluşan sistemlerdir. Jessour sistemi ise bariyer, teras ve toplama alanından oluşan hidrolik birimdir. Bariyerin görevi toprak parçaları ile yüzey akıs sularını tutmak olup, fazla suyun boșaltılması için ana ve yan dolu savaklar bulunmaktadır. Zeytin, incir, badem ve hurma gibi meyve ağaçları ile baklagillerin (bezelye, nohut, mercimek) yetiştirilmesi genel olarak bariyere yakın yerlerde olmaktadır. Geri kalan alanda ise buğday, arpa, çavdar gibi tahıl ürünleri yetiştirilmektedir. Suyun toplandığı bölgede doğal suyolları bulunmaktadır (Ekinci, 2015) (Șekil $5 c, d)$. 

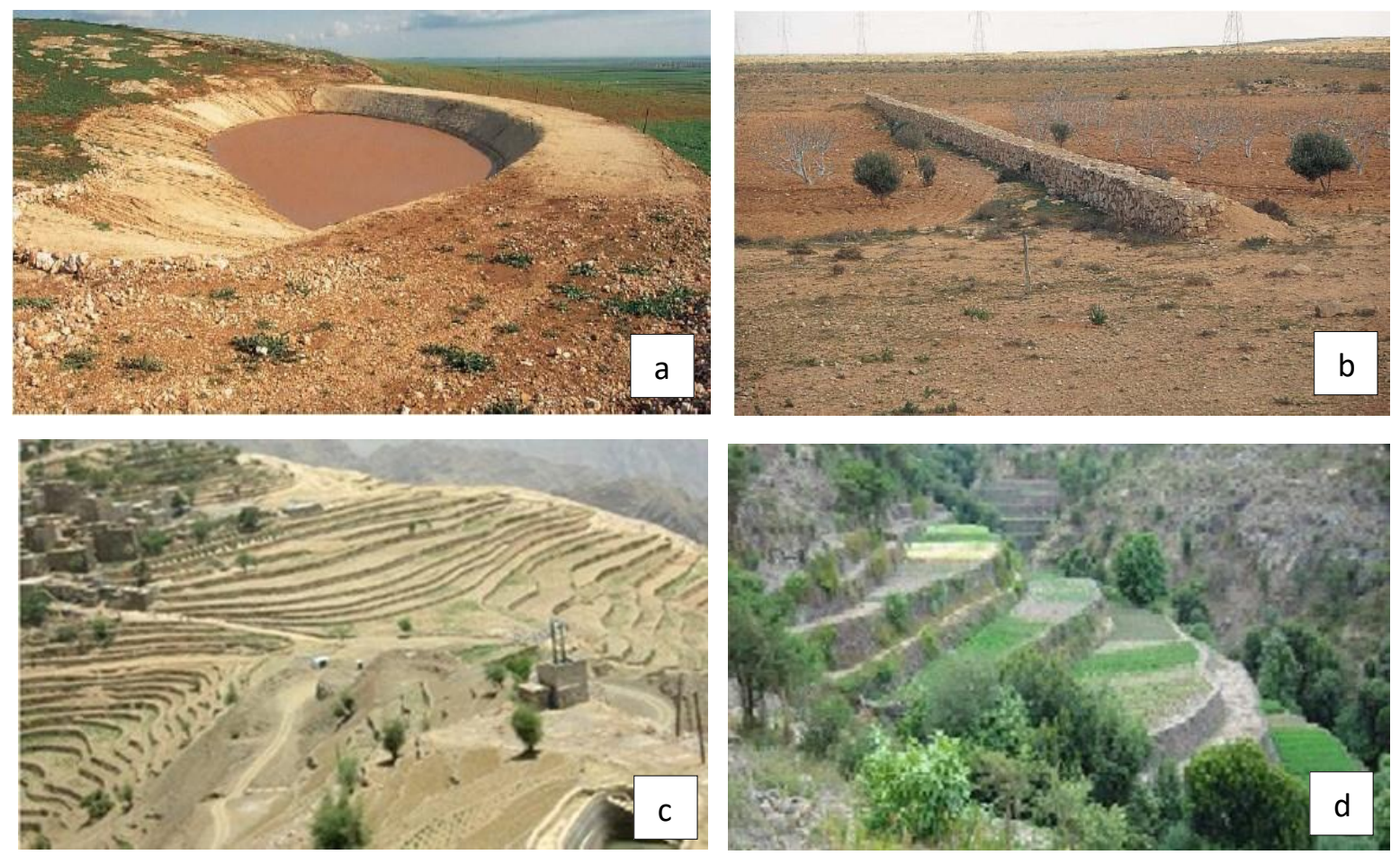

Şekil 5. Vadi Tabanı Sistemleri (Ekinci, 2015), a) Suriye'deki küçük çiftlik göleti (Ekinci,2015), b) Mısırı́n kuzeybatısındaki vadi tabanı taş duvarları (Ekinci,2015), c,d) Yemen'de bulunan teras sistemleri

\subsubsection{Vadi Dıșı Sistemler}

Bu sistemde hasadı yapılan yağmur suyu vadi tabanı dıșında uygulanmakta, bu sistemdeki yapılar vadideki suyun doğal akıșından çıkarılıp yakınlardaki tarıma elverișli arazilere akmasını sağlamaktadır. Bu sistem benzeri yapılar, yağmur suyu toplamak için de kullanılabilir (Ekinci, 2015).

\section{Su Dağıtım Sistemleri}

Bu teknik ile vadide akmakta olan suyun bir bölümü doğal akış bölgesinden çıkarılarak su yakınlarda bulunan bölgelere yönlendirilerek bu bölgelerdeki tarım ürünleri için kullanılmaktadır. Yönlendirilen su bu bölgede yetişen bitkilerin yalnızca köklerinde depolanmaktadır. (Ekinci, 2015) (SSekil 6).

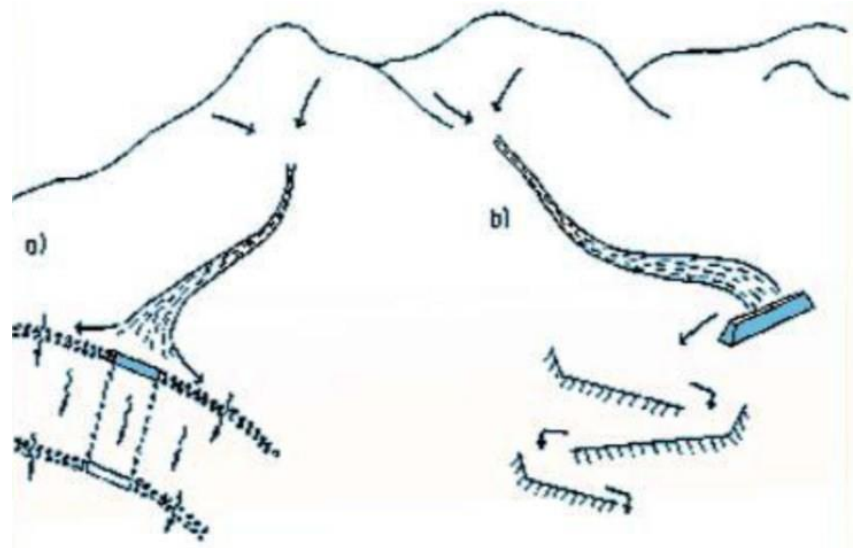

Şekil 6. Su dağıtım sistemi basit şeması (Ekinci, 2015) 
Yağmur Sularının Hasadı ve Aktif Olarak Tarımsal Sulamada Kullanılması

Havuzlar (Su Tankları)

Afrika'nın kuzeyinde taş duvardan yapılan ve "Roma Havuzları" olarak adlandırılan bu havuzlar, vadilerden saptırllan veya büyükçe bir su toplama bölgesinden yüzey akışı ile eğimli alanlarda toprağın kazılmasıyla oluşturulan toplama bölgeleridir. Hindistan'da üç milyon hektarlık bölgede sulama bu tanklar ile yapılmaktadır. Sudan, Ürdün ve Suriye gibi yerlerde ise genellikle büyük havuzların aksine küçük havuzlar daha çok bulunmaktadır (Ekinci, 2015).

\section{Yamaç Akış Sistemleri}

Bu sistemde kullanılan küçük aktarma hatları ile eğimi uzun tepe sonundaki ekili bölgelere su yönlendirilmektedir. Bu sistem yıllık yağış miktarının 200 ila $600 \mathrm{~mm}$ arasında ve eğimin \%10 ve daha fazla olduğu bölgelerde uygulanmaktadır" (Ekinci, 2015).

\section{DÜNYADA YAĞMUR SUYU HASADI VE TARIMSAL ALANDA KULLANIMI}

Ekosistem dinamiklerini etkileyen insan faaliyetleri sonucu kurak ve yarı kurak bölgelerde yapılmaya çalışılan tarımsal faaliyetlerde yağmur suyu hasadı çalışmaları ile verimde artış gözlendiği ve su kullanımının azaldığı gözlemlenmiştir.

Dünya'da çoğu ülkede yağmur suyu hasadı ile tarımsal sulama yapılmaktadır. Yağmur suyu toplama teknolojisi, kurak ve yarı kurak bölgelerde tarımsal verimliliği büyük ölçüde artırmaktadır. Aynı zamanda, bu sistem bu bölgelerde temiz içme suyuna olan ulaşılabilirliği kolaylaştırmaktadır (Unami vd., 2015). Tarımsal sulama nedeniyle yüzey sularında azalma görüldüğü, Çin'de yapılan yağmur suyu hasadı ile su kullanımının azaldığı bildirilmiştir (Wu vd., 2015). Kuraklığın yaşandığı bölgelerden olan Mısır'ın El-Beheira kentinde yağmur suyu hasadı ile su mevcudiyeti ve arazi verimliliğinde artış sağlanmıștır (Mahmoud vd., 2016).

Etiyopya'da yapılan çalışmada yağmur suyu hasadı ile ekosistem korunarak toprağın nemi artmıș, yeraltı su seviyesi yükselmiş, daha az akış ve daha yüksek verim sağlanmıștır (Yosef vd., 2015) (Şekil 7). Tarımsal su kıtlığının yaşandığı Sahra altı Afrika'da, yağışlar mevsimlere göre değişkenlik gösterdiğinden, bu bölgede yağmur suyu hasadı için potansiyel bulunmaktadır (Russo vd., 2014). Ürdün'ün Kafrin bölgesinde yapılan yağmur suyu hasadı ile arazinin 3-4 yıl içinde yeşillendiği, bu süre zarfından sonra yapılan gözlemlerde ise oluşturulan sistemin kendiliğinden çalışarak toprak (humus) meydana gelmesinin devam ettiği gözlemlenmiştir (URL 3).

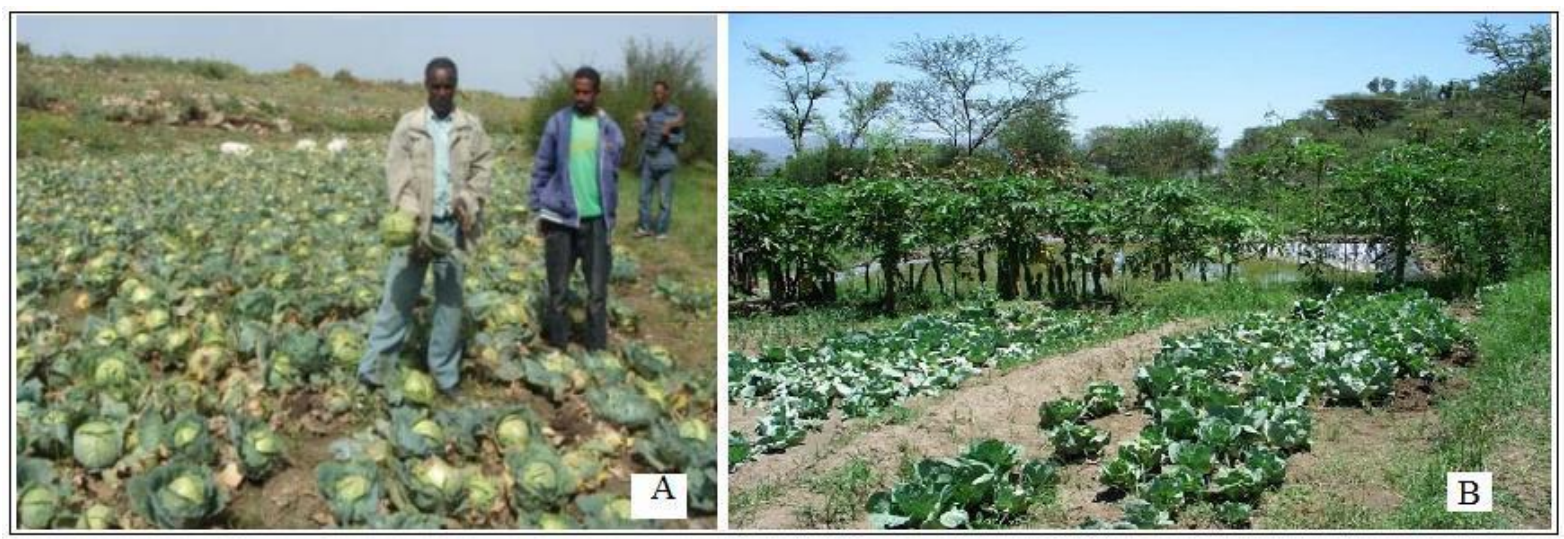

Şekil 7. Etiyopya'da yağmur suyu hasadı sonrası gelișen bir arazi (Yosef vd., 2015)

\section{TÜRKIYE'DE YAĞMUR SUYU HASADI VE TARIMSAL ALANDA KULLANIMI}

Türkiye'de yağmur suyu hasadı ile tarımsal alanda sulama çalışmaları kısıtlıdır. Tarımsal alandan ziyade bahçe ve küçük alanlarda yapılan çalışmalar mevcuttur. Bunlardan İzmir'in Bayındır ilçesi Dernekli Köyü Mersinli (Marmariç) bölgesinde oluşturulan yerleşim yerinde 

yağmur suyu hasadı ile sulama yapılmaktadır (URL 4). Sakarya Üniversitesi kampüsündeki yeşil alanların sulanmasında yağmur suyu hasadı ile elde edilen su kullanılmasına yönelik çalışmalar mevcuttur (Eren vd., 2016). Yine DSİ tarafından başlatılan Göl-Su projesi ile 1001 adet gölet ve sulama tesisi ile depolanan yaklaşı 600 milyon $\mathrm{m}^{3}$ su ile yaklaşı 1,7 milyon dekar tarım alanın sulanması ve taşkından korunması planlanmaktadır (URL 5) (Şekil 8).

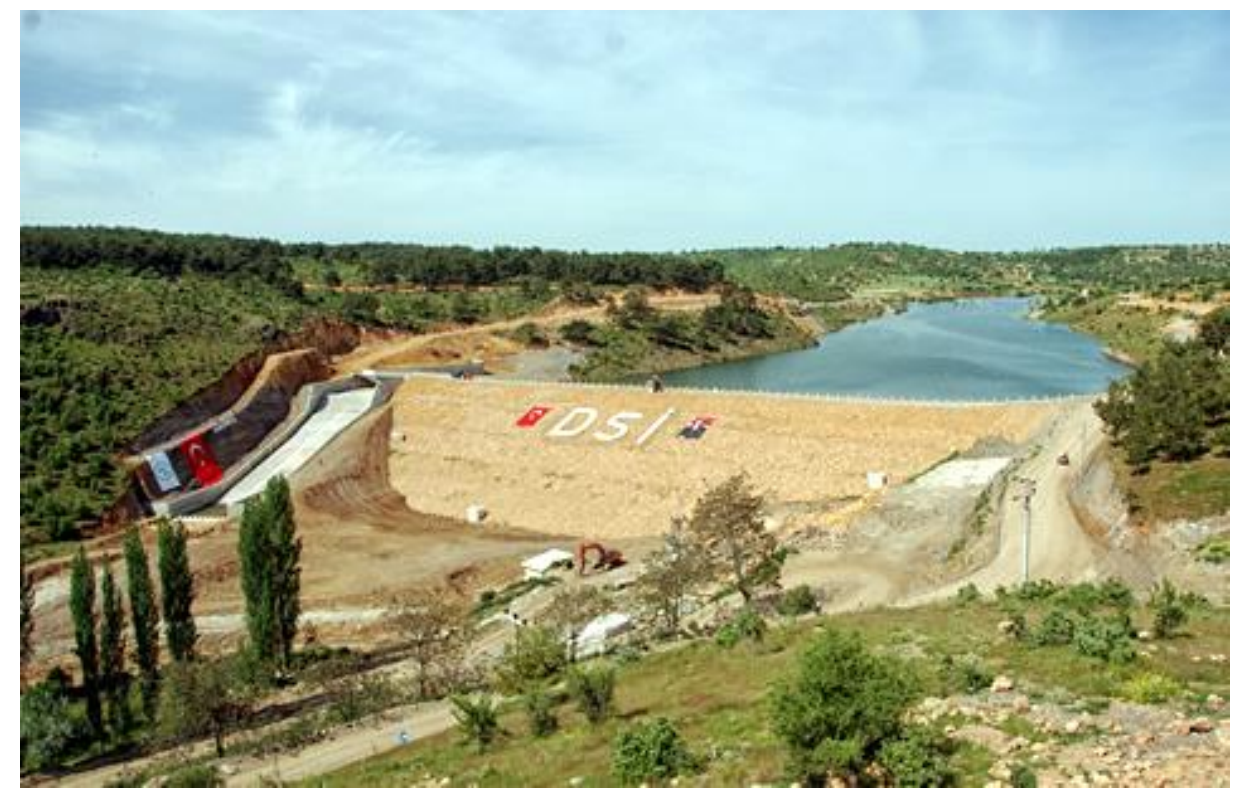

Şekil 8. DSİ tarafından yapılan Göl-Su projesi (URL 3)

\section{SONUÇ VE ÖNERILER}

Su insanlık için çok önemli bir kaynak olup küresel ısınma, iklim değişikliği, israf ve nüfus artışı sonucu daha da değerli bir kaynak haline gelmektedir. Dünyanın yaklaşık üçte ikisinden fazlası suyla kaplı olmasına rağmen oranın çok az bir kısmı kullanılabilmektedir. Ayrıca suyun büyük bir bölümü gereksiz bir biçimde tüketici ihtiyaçları için harcanmakta ve israf edilmektedir. Dünya'nın bazı kurak ve yarı kurak bölgelerinde yapılan yağmur suyu hasadıyla bu bölgelerde daha verimli bitki yetiştirildiğini gözlemlenmektedir. Bunun sonucu olarak erozyon azalmakta, yer altı sularının aşırı tüketiminin önüne geçilmektedir. Yapılan çalışmalarda yağmur suyu hasadı ile kurak alanlarda, ağaçların yetiştiği ve ormanlaşmanın başladığı gözlemlenmiştir. Ülkemiz ise yeraltı ve yerüstü su kaynakları bakımından zenginlik gösterse de suyun yanlış kullanımı sonucu su seviyeleri gittikçe düşmektedir. İlerleyen yıllarda küresel ısınma sonucu meydana gelecek iklim değişikliği daha çok hissedilecek olup, bu durumun ciddiyetini çok daha önemli hale getirecektir. Ülkemizde çok yaygın olarak kullanımı olmayan yağmur suyu hasadı yöntemi, kurak ve yarı kurak bölgelerde karşılaşılan sorunların çözümünde etkili olacaktır. Ayrıca yağmur suyu hasadında Dünya'da uygulanan standartları yakalayabilmek için başta eğitim olmak üzere; araştırma-geliştirme, yatırım faaliyetleri, kongre, bilgi şöleni gibi tanıtıcı çalışmalar ile yağmur suyu hasadı ile ilgili kanuni düzenlemeler yapılarak suyun daha verimli kullanılması sağlanarak gelecekte su sıkıntısının azaltılması mümkün olabilecektir.

\section{KAYNAKLAR}

Benliay, A. (2017, Aralık). Su Varlığı. Plant Dergisi.

Ekşi, M., Yılmaz, M. ve Özden, Ö. (2016). Yağmur bahçelerinin nicel değerlendirilmesi: İstanbul Üniversitesi Orman Fakültesi Örneği. Journal of the Faculty of Engineering and Architecture of Gazi University, 31(4), 1113-1123.

Ekinci, B. (2015). Su Kaynaklarının Verimli Kullanılmasına Yönelik Örnek Ülke Uygulamaları ve 
Yağmur Sularının Hasadı ve Aktif Olarak Tarımsal Sulamada Kullanılması

Ülkemizde Bu Çalışmaların Uygulanabilirliği (Uzmanlık Tezi, Ankara).

http://suyonetimi.ormansu.gov.tr/Libraries/su/Burak EK\%C4\%B0NC\%C4\%B0-

Uzmanl\%C4\%B1k Tezi.sflb.ashx (Son Erişim Tarihi: 04.06.2018)

Eren, B., Aygün, A., Likos, S. ve Damar, A., İ. (2016). Yağmursuyu Hasadı: Sakarya Üniversitesi Esentepe Kampüsü Potansiyelinin Değerlendirilmesi. International Journal of Engineering and Technology Research, 1(1), 1-5.

Mahmoud, S., H., Adamowski, J., Alazba, A.A. and El-Gindy,A., M. (2016). Rainwater harvesting for the management of agricultural droughts in arid and semi-arid regions. Paddy Water Environ, 14, 231-246.

Russo, T. Alfredo, K. and Fisher, J. (2014). Sustainable Water Management in Urban, Agricultural, and Natural Systems. Water, 6(12), 3934-3956.

Unami, K., Mohawesh, O., Sharifi, E., Takeuchi, J. and Fujihara, M. (2015). Stochastic modelling and control of rainwater harvesting systems for irrigation during dry spells. J. Clean. Prod., 88, 185-195.

Wu, Y., Jia, Z., Ren, X., Zhang, Y., Chen, X., Bing, H. and Zhang, P. (2015). Effects of ridge and furrow rainwater harvesting system combined with irrigation on improving water use efficiency of maize (Zea mays L.) in semi-humid area of China. Agric. Water Manage., 158, 1-9.

Yosef, B., A. and Asmamaw, D.,K. (2015, February). Rainwater harvesting: An option for dry land agriculture in arid and semi-arid Ethiopia. International Journal of Water Resources and Environmental Engineering, 7(2),17-28.

URL 1, https://www.iddef.org/yagmur-hasadi (Son Erişim Tarihi: 10.10.2018)

URL3, http://permakulturplatformu.org/2012/10/11/colu-yesillendirmek

(Son Erișim Tarihi: 05.06.2018)

URL 2, https://www.pad.org.tr/yagmur hasadi_kitabi.pdf (Son Erişim Tarihi: 05.06.2018)

URL 4, https://surdurulebiliryasam.wordpress.com/tag/marmaric/ (Son Erişim Tarihi: 04.06.2018)

URL 5, http://www.dsi.gov.tr/projeler/gol-su-projesi (Son Erişim Tarihi: 04.06.2018) 